Universidad de Lima

Facultad de Comunicación

Carrera de Comunicación

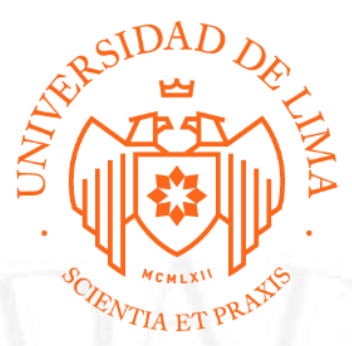

\title{
REALIZACIÓN DE MANUAL DE IDENTIDAD VISUAL PARA LA MARCA CREMASCOTAS
}

Trabajo de Suficiencia Profesional para optar el Título Profesional de Licenciada en Comunicación

\section{Brenda Yacira Montenegro Gutierrez \\ Código 20122913}

\author{
Asesor \\ Miguel Gustavo Bernal Quijano
}

$$
\text { Lima - Perú }
$$

Febrero del 2020 


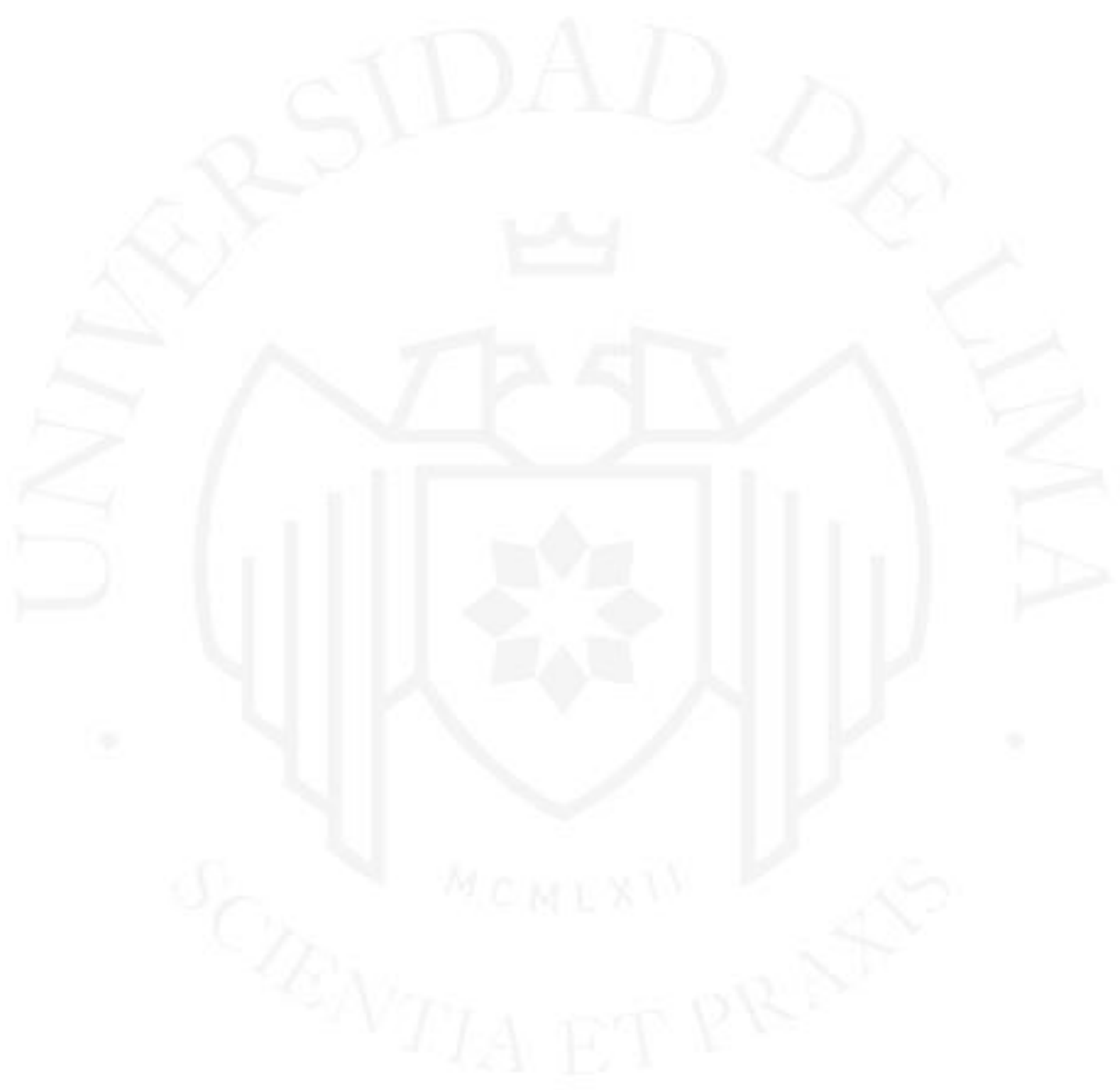




\section{MAKING VISUAL IDENTITY MANUAL FOR THE CREMASCOTAS BRAND}




\section{TABLA DE CONTENIDO}

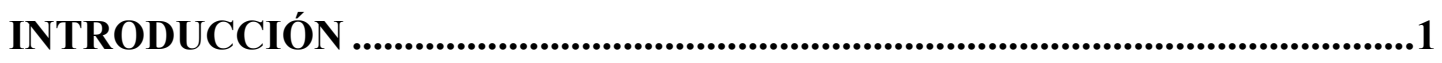

CAPÍTULO I: ANTECEDENTES DEL TRABAJO ......................................2

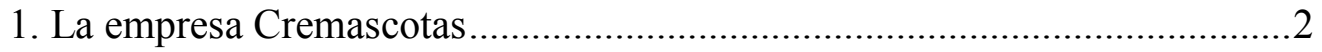

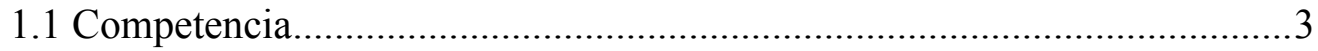

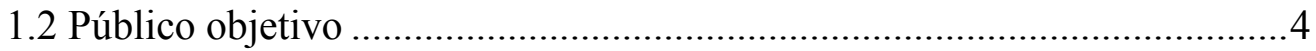

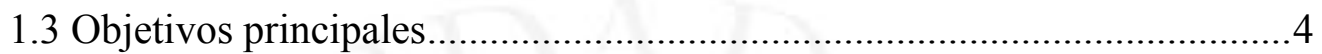

1.4 Diagnóstico de la empresa ...................................................................4

1.5 Estrategia de comunicación y de marca ...................................................5

CAPÍTULO II: REALIZACIÓN Y SUSTENTACIÓN..........................................6

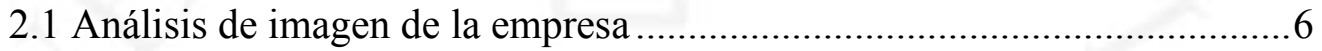

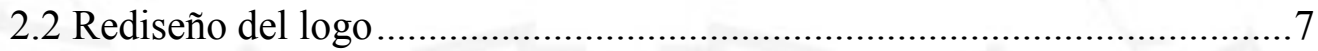

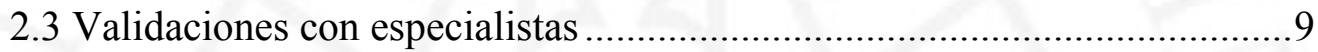

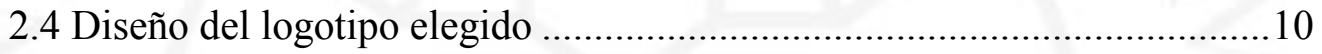

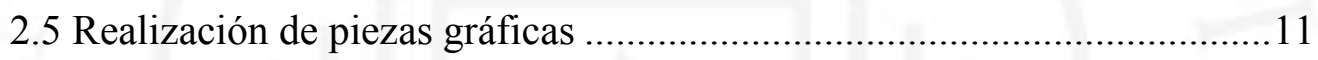

2.6 Realización del manual de marca.............................................................11

2.7 Validación de manual y logo con especialistas........................................12

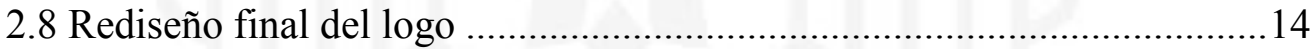

CAPÍTULO III: LECCIONES APRENDIDAS .....................................................17

CAPÍTULO IV: LOGROS Y RESULTADOS ................................................18

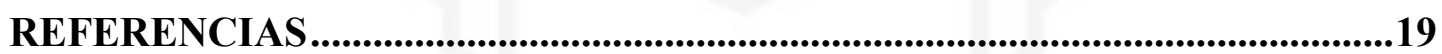

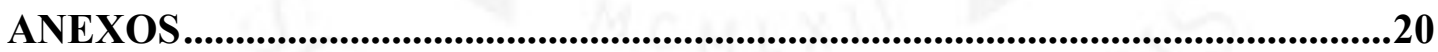




\section{ÍNDICE DE FIGURAS}

Figura 2.1. Logotipo antiguo de la empresa Cremascotas ....................................6

Figura 2.2. Primeros bocetos en base a la información recabada en la encuesta...........8

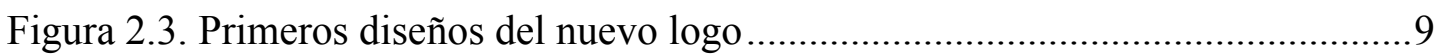

Figura 2.4. Logotipo elegido con los colores iniciales .......................................... 11

Figura 2.5. Logotipo con la sílaba CRE sobre la línea base ....................................12

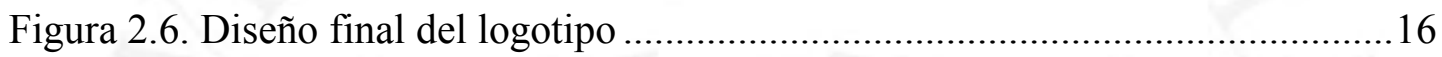




\section{ÍNDICE DE ANEXOS}

Anexo 1. Encuestas hacia el público objetivo

Anexo 2. Entrevistas a especialistas para validar el logotipo (2018)

Anexo 3. Entrevista a especialistas para validar el manual de marca y el logotipo renovado (2019)

Anexo 4. La encuesta hacia el público objetivo para saber qué opinan acerca del logotipo

Anexo 5. El logotipo del año 2018 se utilizó en las dos redes sociales: Instagram y

Facebook 
Link del material audiovisual: $\underline{\text { Cremascotas. Manual de identidad. }}$ 


\section{RESUMEN}

El presente proyecto justifica y describe el rediseño y sistematización de la identidad visual de Cremascotas, una marca ya existente en el mercado del norte peruano. Tiene como objetivo reforzar y comunicar la personalidad de la marca a través de la renovación de su logotipo, trabajo que se consolidará en un manual de identidad visual, producto que buscará mejorar el sistema de branding de la marca para alcanzar awareness en la mente del consumidor y que su ecosistema visual sea asociado fácilmente con los servicios que brinda la empresa. 


\section{INTRODUCCIÓN}

En un mercado donde el creciente amor por las mascotas es evidente y el sentimiento animalista se posiciona cada vez con mayor fuerza en la conciencia colectiva, la oportunidad para una empresa dedicada a velar por el duelo de las mascotas fallecidas es inmejorable. Uno de estos emprendimientos es Cremascotas, una empresa que funciona en el norte del país y que enfrenta una necesidad imperiosa producto de esta coyuntura, para hacer de su marca visual una más interesante, sólida y profesional, para que a mediano y largo plazo llegue a asentarse y posicionarse en este tan fértil mercado.

A continuación, encontraremos los antecedentes, las necesidades y los objetivos que motivaron la sistematización y rediseño de la identidad visual de Cremascotas en la búsqueda de forjar una marca efectiva, sólida y atractiva para su público objetivo. 


\section{CAPÍTULO I: ANTECEDENTES DEL TRABAJO}

\section{La empresa Cremascotas}

La empresa Cremascotas, con sede en Chiclayo y con servicios hasta Piura (aún no posee un establecimiento allí), es una empresa fundada el 01 de Mayo del 2012, dedicada a ofrecer servicios de cremación de mascotas domésticas. Sus inicios fueron muy particulares debido a que el servicio se inició sobre un trabajo de mapeo de zonas con alta densidad de veterinarias, establecimientos que suelen requerir el servicio de cremación. En un principio la empresa solo contaba con dos personas, una vendedora y un chofer, quienes salían por las calles a realizar una labor de volanteo y perifoneo comunicando sus servicios. Su objetivo era registrar cada una de las veterinarias hasta lograr elaborar un banco de datos que las identificara.

En el año 2014 y 2015 se fundó la empresa con el nombre "Cremascotas", una de las empresas que conforman el grupo Montenegro Gutiérrez en el mercado Chiclayano, con poca acogida y ventas hasta ese momento. Su objetivo era elevar su reconocimiento a través de un servicio poco usual y un negocio innovador.

En el año 2016, la propuesta de la empresa era continuar con la difusión de los servicios de Cremascotas elevando su personal de ventas y, comparando con el año 2015, las ventas y la acogida del público subieron increíblemente.

Entre el año 2017 y 2018 el progreso fue, aunque lento, extraordinario, éxito que fue el detonante para elevar las expectativas y seguir mejorando en los siguientes años hasta lograr los objetivos propuestos.

Y al igual que en años anteriores, el 2019 también reveló un crecimiento en su cartera de clientes de la mano con el mayor reconocimiento de la marca, haciendo de esta una más recordada.

Vale añadir que en esta etapa es cuando el trabajo de comunicación interviene, realizándose experimentos y rediseños al logotipo, así como un mayor trabajo de piezas de comunicación que, poco a poco, llevan a cabo el cambio de imagen gráfica que se había trazado. Hoy en día la empresa ha llegado a expandir sus servicios a Piura mediante puntos de venta directa y tiene intenciones de llegar, en el mediano plazo, a todo el norte peruano. 
Aparentemente el crecimiento constante de la empresa se debió al nicho que la gestión de marca ha sabido aprovechar: Cremascotas representa una forma amigable y única de recordar a aquel amigo fiel que compartió nuestras alegrías y formó parte de la familia. El lema que la empresa maneja hoy en día es: "Nuestra mascota, nuestra fiel compañera".

Para la incineración, Cremascotas cuenta de un horno ecológico, urnas para cada raza y sexo, movilidad propia para trasladar a las mascotas fallecidas hacia el lugar de la cremación y el otorgamiento de un certificado de cremación como un detalle memorable de la mascota. Es importante resaltar que la empresa posee una fuerte ventaja diferencial por ser un tipo de servicio inusual en el Perú, más aún en su mercado inicial Chiclayo, pues hay muy pocos centros en donde se incineran animales domésticos que cuenten con un horno ecológico y personalizado para las urnas. No es así en otros países donde sí se demanda mucho este tipo de servicio.

Pero Cremascotas no se limita solo a brindar un servicio que viene satisfaciendo continuamente a sus clientes, porque la sola cremación cuenta con los cuidados y requerimientos necesarios para llevar bienestar y calma espiritual a sus usuarios. Cremascotas también se preocupa por cuidar al medio ambiente ya que la cremación garantiza que las cenizas de la mascota se encuentren libre de bacterias. Las urnas son de un material ecológico que conservan los restos del animal de manera segura, con el fin de mantener la cercanía con el dueño sin propagar malos olores o enfermedades. Últimamente la empresa ha optado por brindar un servicio adicional al cliente con un seguro de protección que cubre a tu mascota para los gastos en el momento de su cremación.

\subsection{Competencia}

La competencia de la empresa, son personas que tienen esa ideología de preferir enterrar a sus mascotas en vez de cremar, ya que no están de acuerdo con esa modalidad nueva que se está usando. Sin embargo, no hay empresas de otro rubro en la ciudad de Chiclayo ni en Piura (donde la empresa se quiere expandir) mercado que está abierto para Cremascotas como una opción más. 


\subsection{Público objetivo}

Según IPSOS: "En el Perú y específicamente en Lima, existen más hogares con mascotas que hace 20 años. En las encuestas de 1995, el indicador marcaba 52\% de las familias; en el 2005, subió a 55\% y en el 2014, registró 58\% (3). De acuerdo con la estadística, el perro sería el animal doméstico más popular en los hogares limeños, seguido por los gatos. Los canarios, pericos y peces también están presentes en la lista pero con muy pocas menciones (Ipsos, 2015). Cremascotas trabaja con todo tipo de mascotas.

El público objetivo es amplio y se define como toda familia o personas que cuenten con una mascota en casa, de nivel socioeconómico A y B y, por ahora, que resida en la zona norte del Perú, en Chiclayo y Piura específicamente. Su estilo de vida es variado, aunque el sentimiento animalista y cariño creciente por las mascotas se desarrolla con mayor énfasis en personas jóvenes y adultas independientes que tiene pasión por los animales.

\subsection{Objetivos principales}

El Objetivo Principal del Proyecto es posicionar a Cremascotas como una marca sólida, amigable y cercana a través del mejoramiento y rediseño de su logotipo y la sistematización de su imagen en un manual de identidad visual.

\subsection{Diagnóstico de la empresa}

Gracias a una apreciación efectiva e inteligente del mercado chiclayano, Cremascotas ha logrado ingresar de manera efectiva en el mercado de mascotas, pero su imagen visual y trabajo de marca no ha sido desarrollado con el mismo ahínco y profesionalismo. El logotipo creado por el dueño de la empresa, por ejemplo, parecía ser de una veterinaria y no tenía la estética apropiada para apoyar el dolor y luto que trae consigo la pérdida de una mascota: era frío y lejano a nivel formal. Igualmente, las piezas gráficas promocionales eran desordenadas y meramente informativas, descartando cualquier trabajo con una estética y un significado que aporte posicionar a la marca. 
Era evidente entonces que la empresa adolecía de una falta de trabajo comunicativo, sobre todo en lo que a imagen visual de marca se refería. Por esa razón se requirió el servicio de rediseño de logotipo, para buscar brindar una impresión de mayor sofisticación y seriedad a través de los elementos constitutivos de su imagen, el color y la tipografía. De igual forma se solicitó desarrollar banners para eventos, volantes, tarjetas de presentación, certificados de cremación, stands, bolso para el personal de trabajo y portarretratos, todas piezas gráficas que han sido solicitadas recientemente para brindar una sólida imagen y un servicio más completo hacia el cliente. Todos los lineamientos que han regido estos últimos trabajos se sistematizan y ordenan en un manual de identidad corporativa, producto principal del proyecto que acompaña este informe.

\subsection{Estrategia de comunicación y de marca}

Un objetivo primordial de mercado de la empresa "Cremascotas" es darse a conocer en todos los establecimientos veterinarios locales de la ciudad de Chiclayo. Se piensa conseguir esta meta mediante una campaña de relanzamiento, intentando refrescar la marca a través de un reforzamiento de sus valores y la personalidad que ha ganado la marca frente a su público objetivo. Por esa razón se ha planteado como lineamiento estratégico de comunicación sistematizar la imagen visual de la marca para que, de ahora en adelante, mantenga cierta unidad y forje a mediano plazo una marca más sólida y reconocible. Esta sistematización de las piezas gráficas abarca también una mayor difusión de la comunicación offline y online que hará que la marca se modernice, siga las tendencias del mercado y llegue a un público más amplio y joven. Es así que la estrategia de marca de la empresa Cremascotas es la de redefinir el comportamiento y las acciones de las comunicaciones gráficas de la empresa partiendo de su propuesta de valor: en el mercado chiclayano y piurano no hay un servicio que brinde la cremación de mascotas domésticas y para llevar a cabo esta tarea se elaboró precisamente un manual de la imagen visual de la empresa. 


\section{CAPÍTULO II: REALIZACIÓN Y SUSTENTACIÓN}

\subsection{Análisis de imagen de la empresa}

El año 2018, se analizó la oportunidad de cambiar la imagen gráfica de la empresa, tanto del logotipo como de las siguientes piezas gráficas y material audiovisual para sus redes sociales. Para ello se decidió elaborar un manual de marca y se requirió los servicios de una profesional, ya que la compañía no contaba con personal capacitado para ese fin.

El logotipo de la empresa lucía un concepto totalmente alejado de los servicios que ofrecía (Figura 2.1). Cambiar este logotipo fue la primera tarea que se encargó realizar.

Figura 2.1

Logotipo la empresa

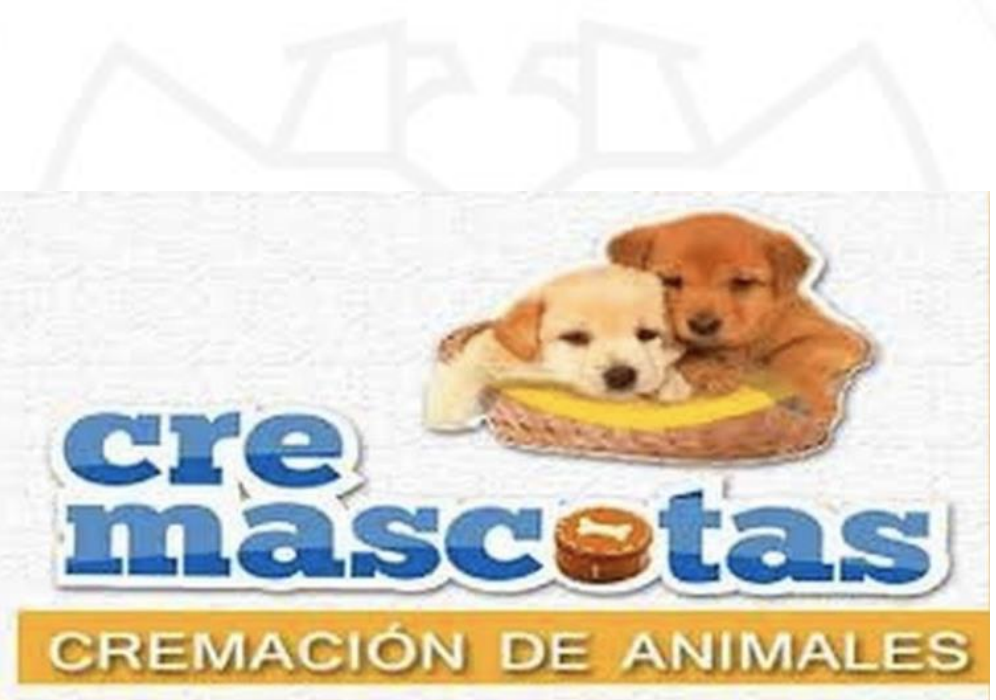

antiguo de

Cremascotas 
Para iniciar esta labor se debía contar con las opiniones del público objetivo. Se trataba de averiguar, en primera instancia, cuáles eran aquellas ideas que conformaban el obstáculo estratégico que alejaba a cierto público de contar con los servicios de la empresa.

En total se realizaron 35 encuestas a hombres y mujeres con mascotas. Los resultados revelan que, si bien la mayoría aprueba y considera a la cremación como una opción sana y adecuada, muchos no tienen pensado hacerlo cuando llegue el momento.

Las razones para rechazar la cremación parecen ser de índole religioso (una persona menciona que no lo haría por ser católica) y económico (mencionan en la encuesta que debe ser caro). Mientras tanto, aquellos que aprueban la cremación (aunque mencionan que no están seguros de hacerlo) argumentan que es más sano y práctico para los usos habitacionales modernos (no se les puede enterrar si vives en departamento), es una forma de mantener siempre cerca a sus mascotas y le adosan diversas cualidades ecológicas (han escuchado que sirve para abonar árboles, por ejemplo).

A continuación, mostramos cuáles fueron las preguntas de la encuesta y sus resultados se incluirán en el capítulo Anexos:

1) ¿Tienes mascotas? (si tu respuesta es "NO", se acaba acá la encuesta)

2) ¿Qué tipo de mascotas tienes?

3) Si tu mascota falleciera, ¿Qué piensas hacer?

4) ¿Dónde cremarías o enterrarías a tu mascota?

5) ¿Quién decide cremarlo o enterrarlo?

6) ¿Estás de acuerdo con esta nueva modalidad de "cremar mascotas"? ¿Por qué?

\subsection{Rediseño del logo}

Con base en la información recabada se realizaron un par de bocetos (Figura 2.2) tomando en cuenta apaciguar los sentimientos religiosos con una imagen más juguetona y fresca, y reforzar también la cercanía y accesibilidad para que aparecer como un servicio no tan caro. 
Se quería, a través de una nueva tipografía, paleta de colores e iconografía del isotipo, lograr resaltar esas sensaciones. Según Moira Cullen (vicepresidenta, Global Beverage Design PepsiCo) "El diseño diferencia y representa los valores intangibles (emoción, contexto y esencia) que más importan a los consumidores" (Alina Wheeler, 2018). 
Figura 2.2

Primeros bocetos en base a la información recabada en la encuesta

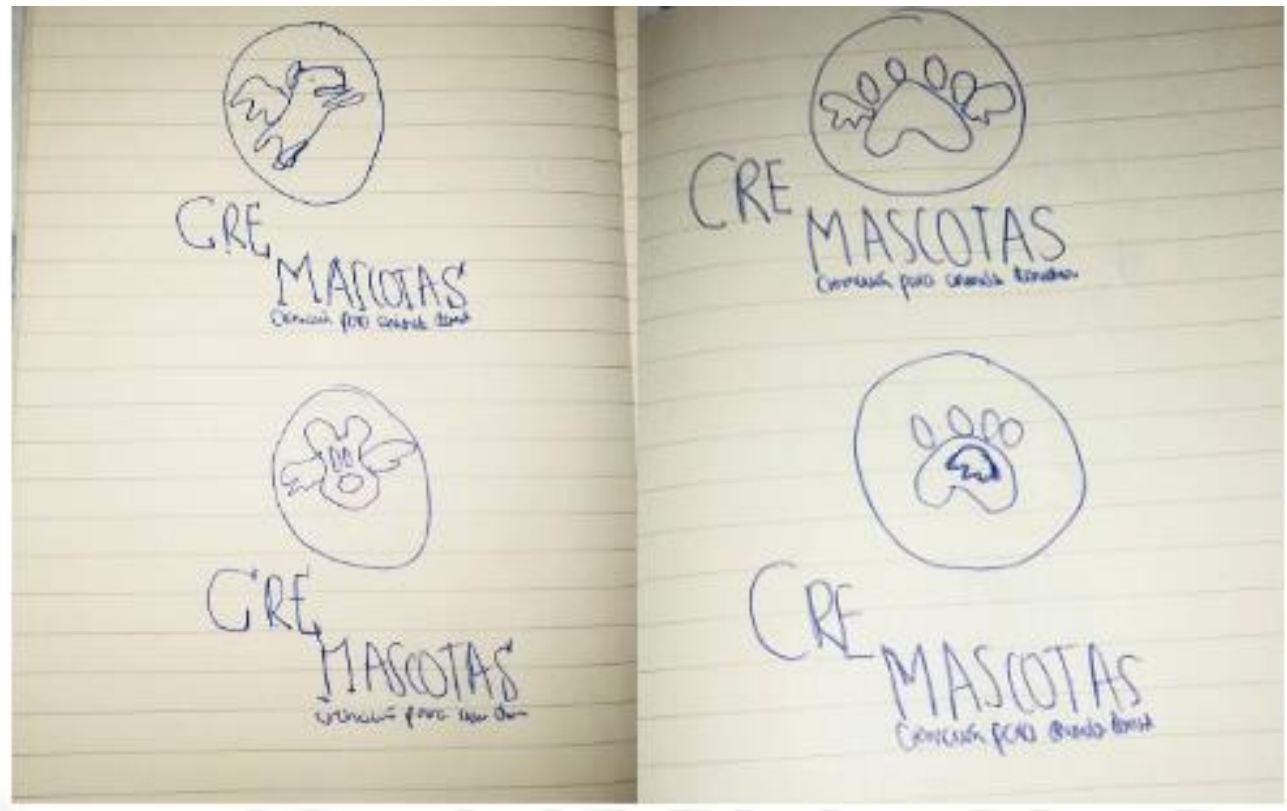

Una de las primeras exigencias del cliente fue incluir en el logotipo un texto que precise el rubro del negocio, la cremación de mascotas, para paliar así sus temores de que, como con el logotipo anterior, confunda al público con los servicios prestados por una veterinaria.

Luego se procedió a formalizar los diseños en Adobe Illustrator, de manera que estos presenten sus cualidades de mejor manera.

Se incluyeron íconos que se relacionen con mascotas, unas alas para generar la sensación de cielo y ángeles de la guarda, elemento utilizado para encaminar la personalidad hacía la seguridad que este escenario ofrece (en el cielo todos descansan y son felices) y, finalmente, se decidió utilizar espacios circulares como figuras centrales y contenedoras, espacios que recibirán a los elementos mencionados anteriormente.

Las circunferencias generan movimiento y dinamismo y están exentos de vértices que pueden generar sensaciones agresivas (Figura 2.3). Se probaron dos tipografías, una Neo Grotesca Bold (Helvética), para buscar modernidad y solidez, y una Romana Transicional (Souvenir), para buscar prestigio y confianza. Se usaron colores fríos, como celestes, para dar la idea de cielo y seriedad, junto con tonos neutros como grises, para que los negros y celestes resalten. 
En el libro de diseño de marca se señala que: "El logo de una marca están diseñados con una variedad casi infinita de formas y estilos”.

Los logos de marca pueden asignarse a varias categorías generales. De literales a simbólicos, de aquellos dominados por la palabra a los dominados por la imagen, el universo de los logos de marca se expande día a día”. (Alina Wheeler, 2018)

Figura 2.3

Primeros diseños del nuevo logo

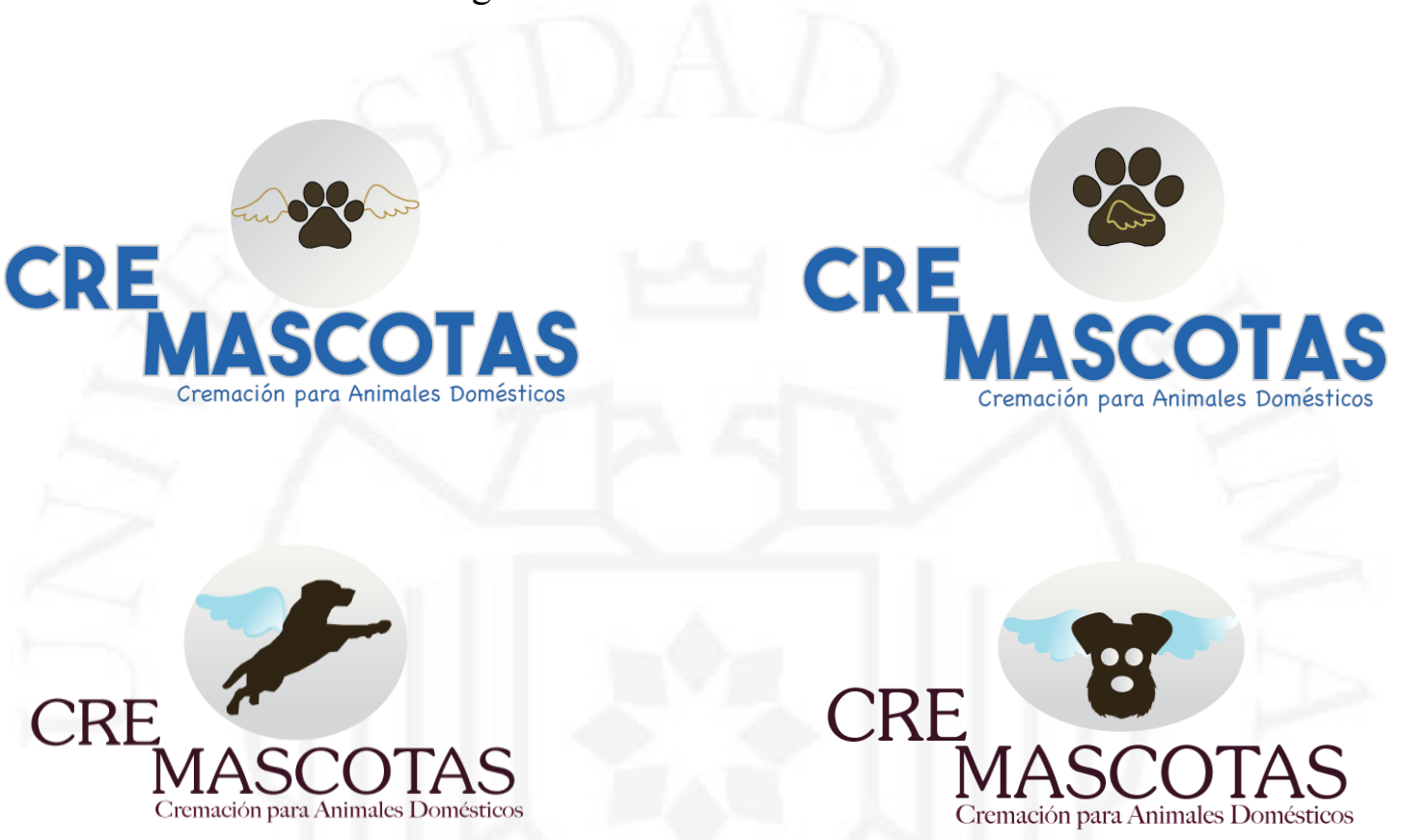

\subsection{Validaciones con Especialistas}

Se decidió validar los bocetos con especialistas en diseño gráfico de la Facultad de Comunicación-Universidad de Lima, entrevistando a los profesores Miguel Bernal y Alberto Matsuura. Sus opiniones están en Anexos. Sobre el logotipo de la patita dentro del círculo acompañado de alas de ángel, Bernal mencionó que se asemejan a una veterinaria mas no a un servicio de cremación de animales y la tipografía es muy dura y áspera al igual que los colores.

Alberto Matsuura opinó que es bien figurativo, pero al usarlo en varios soportes se puede perder porque el color es opaco y no llamativo. Ambos especialistas sugirieron mejorar la tipografía a una tradicional romana, en sus distintas variedades, como la Garalda, Caslon, Souvenir. Además, recomendaron que los colores sean cálidos, con 
matices rojos, naranjas o amarillos porque ayudaría a enganchar con los sentimientos del público objetivo. En cuanto a los otros logotipos que muestra el rostro del perrito encerrado en un círculo acompañado con alas y el del perro volando, ambos especialistas dijeron que representa mayor solemnidad y se relaciona mejor con el rubro de la empresa, pero necesita más color, como el celeste, sugiriendo que el círculo, que representa el cielo, tenga ese tono (celeste) y las alas color blanco en representación de la pureza, y el perrito que sea color cálido, como un marrón rojizo, para mostrarse más agradable y familiar.

\subsection{Diseño del logotipo elegido}

Finalmente se llegó a la conclusión de optar por el perro con alas sobre una circunferencia (Figura 2.4). Pero los colores fueron cambiando. La referencia del cielo celeste y la mascota que se va al cielo, funcionó. Los colores fueron modificándose y el uso del celeste redujo su saturación para representar mayor pureza y la seguridad que genera el concepto de cielo. Este matiz frío busca además presentar una personalidad de modernidad y seriedad que favorece a la percepción del servicio.

El color tiene una larga historia en la pintura cristiana representando las cualidades de la vida celestial, relacionado de manera positiva con una empresa seria de cremación de mascotas. Por otro lado, color marrón es acogedor y representa el matiz del pelaje de muchas mascotas, es familiar y cercano por ser un matiz cálido y contrasta sobremanera con el celeste que es casi su complementario, lo que le da a la silueta del perro una fuerte presencia.

Según el libro de nombre de Psicología del color, se señala que: "el contrario es el azul-marrón en la psicología, brinda un contraste simbólico de espiritual-terrenal, noble-innoble, ideal-real" (Eva Heller, 2012). El blanco combina fácilmente con otros matices y en este caso con los colores fuertes de la silueta del perro, que es el color marrón, y el fondo celeste. Es además un tono carismático ya que alude a las alas de un ángel que se está yendo al cielo, mostrando (de) una forma delicada y pura. Por otro lado, se decidió por la tipografía Souvenir, el cual, según el libro Manual de la Tipografía, "es una romana moderna por su modulación axial y contraste entre los trazos finos y gruesos y la tipografía Athelas, es una romana antigua por su modulación 
inclinada de trazo quebrado y con remates ligeramente desproporcionados (Montesinos, 2003).

Figura 2.4

Logotipo elegido con los colores iniciales

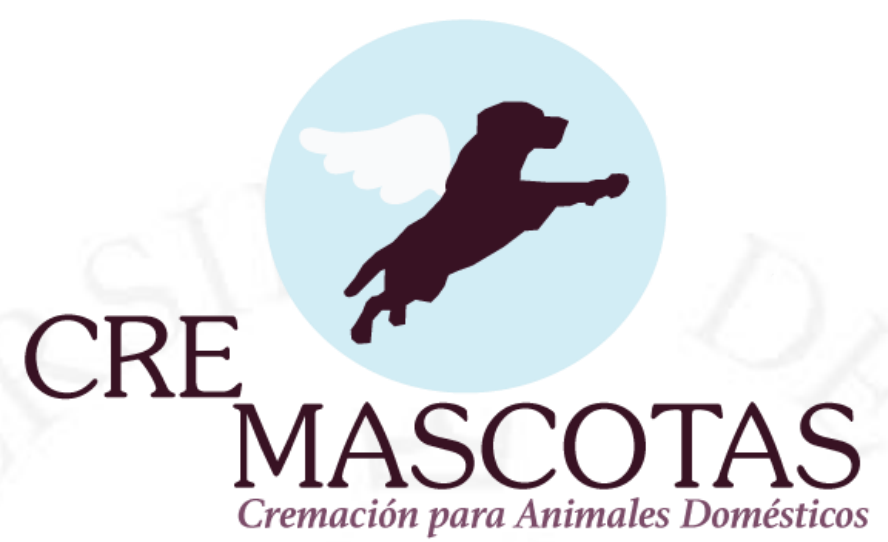

\subsection{Realización de piezas gráficas}

Junto con la realización del logotipo se llevó a cabo la diagramación de diferentes piezas gráficas con la nueva identidad visual. Para las pruebas y realización de bocetos se usaron mock ups para cada pieza gráfica, entre estos: tarjetas de presentación, stand de venta, certificado de cremación, volantes, banners, y polos, siempre de acuerdo a la paleta de colores que poco a poco se iba definiendo (los celestes y marrones fueron cambiando) y a la personalidad que la empresa venía buscando. Fue cuando surgió la necesidad de uniformizar todo este trabajo y garantizar que cualquier pieza gráfica diseñada a partir de ahora mantenga una unidad gráfica. Es por eso que se decidió elaborar un manual de identidad visual. Las necesidades fueron convocando, con cada paso, los productos que los clientes necesitan. Hans-U. Alleman, cofundador de Allemann, Alquimist y Jones, señala al respecto: "Nunca se sabe lo que el proceso va a revelar" (Wheeler, 2018).

\subsection{Realización del manual de marca}

Durante el 2019, se empezó y fue mejorándose la realización del manual de marca. Este no solo iba a contener los lineamientos clásicos del logotipo, también incluiría el uso adecuado de fotografías y un contenido más dinámico y original para enfatizar la 
personalidad de la empresa, haciendo de este manual no solo una guía técnica del uso de logotipo sino también una pieza de promoción publicitaria y de imagen para colaboradores y proveedores.

Entre las cosas que cambiaron en el manual se encontró el logotipo en Souvenir. Ya se había construido uno con la sílaba CRE separada y elevada sobre la línea base del texto, para darle movimiento al logotipo (Figura 2.5), pero luego se encontró que este efecto causaba algunos problemas de equilibrio y no permitía una óptima legibilidad del texto.

Finalmente se cambió y se ubicaron todas las sílabas sobre la línea base principal. Según el libro Manual de la tipografía se señala que: "La tipografía puede definirse como el arte de disponer correctamente el material de imprimir, de acuerdo con un propósito específico, el de colocar las letras, repartir el espacio y organizar los tipos con vistas a prestar al lector con máxima ayuda para la comprensión del texto“ (Luis Martín Montesinos, 2003).

Figura 2.5

Logotipo con la sílaba CRE sobre la línea base

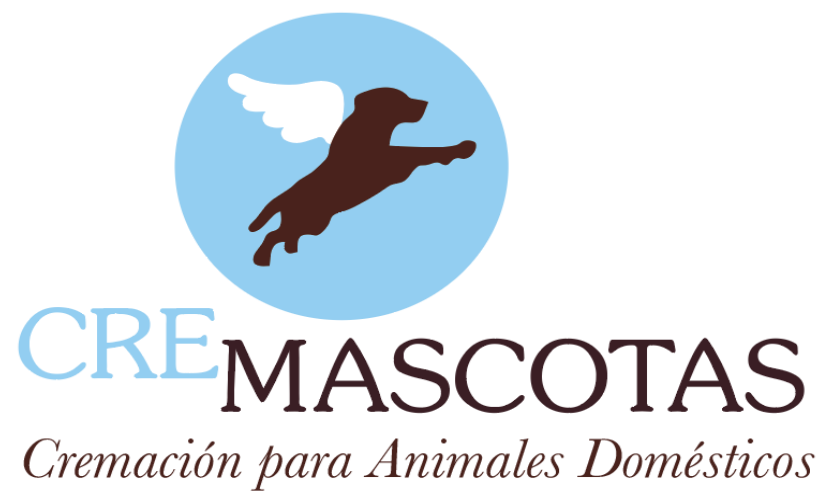

\subsection{Validaciones del manual y logo con especialistas}

Se realizaron validaciones con dos profesores de la Facultad de Comunicación de la Universidad de Lima. Claudia Torres, profesora de Imagen de Marca mencionó no encontrar la silueta del perro bien proporcionada y que debía corregirse detalles en las 
patas de la silueta y que la letra CRE debe resaltar de la misma forma que MASCOTAS en cuestión de color.

En cuanto al manual, recomendó buscar colores complementarios que acompañan al celeste y rojo del logotipo así como cuidar que el logotipo se presente sin variaciones y la mayor cantidad de veces posible en las piezas gráficas mostradas. Por otro lado, el profesor Alberto Matsuura indicó que las fotografías deberían ser netamente peruanas, no de otros países, para que no se pierda el sentido nacionalista de la empresa. Recomendó mejorar la aplicación del logotipo y arreglar problemas en las indicaciones del área de seguridad. Y con respecto al logotipo dijo que este debe ser trabajado de mejor manera para que, con un solo color sólido, llegue a integrarse mejor.

Se realizó una última validación con Javier Custodio, diseñador gráfico de la UPC, quien recomendó que se debe mejorar la sección de usos correctos e incorrectos del logotipo, mostrar los colores Pantone y mejorar la sección de los usos de la tipografía. Las entrevistas se encuentran en la sección de anexos.

Finalmente se realizó una encuesta a un total de 25 personas, hombres y mujeres, para conocer su opinión acerca del logotipo. Las preguntas que se realizaron fueron las siguientes:

1. ¿A qué tipo de empresa cree que pertenece este Logotipo?

2. Es una empresa que se encarga de la cremación de mascotas. ¿Del 0 al 5, qué tanto se asocia este logotipo a la empresa?

3. ¿Del 0 al 5, este logotipo representa una empresa confiable y seria?

4. ¿Del 0 al 5, este logotipo representa una empresa económica y barata?

5. ¿Del 0 al 5, este logotipo representa una empresa amigable y amorosa?

6. ¿Cree usted que, al ver este logotipo, traten bien al cuerpo de tu mascota?

7. ¿Te parece atractivo, te gusta? ¿Qué tanto te gusta el Logotipo? Díganos: ¿Por qué?

8. De la pregunta anterior: Díganos, en 3 palabras: ¿Por qué te gusta el logotipo?

A continuación, presentamos los resultados:

Respuestas a la primera pregunta: 
$\rightarrow 76 \%$ cremación de mascotas. $16 \%$ entierro. $4 \%$ veterinaria y $4 \%$ clínica de mascotas.

\section{Respuestas a la segunda pregunta:}

$\rightarrow 48 \%$ respondieron el número $05.40 \%$ respondieron el número $04.4 \%$ respondieron el número $03.4 \%$ respondieron el número $02.4 \%$ respondieron el número 0 .

\section{Respuestas a la tercera pregunta:}

$\rightarrow 12 \%$ respondieron el número $05.36 \%$ respondieron el número $04.40 \%$ respondieron el número $03.4 \%$ respondieron el número $02.4 \%$ respondieron el número $01.4 \%$ respondieron el número 0.

\section{Respuestas a la cuarta pregunta:}

$\rightarrow 12 \%$ respondieron el número $05.20 \%$ respondieron el número $04.52 \%$ respondieron el número $03.12 \%$ respondieron el número $02.4 \%$ respondieron el número 1.

\section{Respuestas a la quinta pregunta:}

$\rightarrow 28 \%$ respondieron el número 05 . 56\% respondieron el número $04.8 \%$ respondieron el número $03.4 \%$ respondieron el número $01.4 \%$ respondieron el número 0 .

\section{Respuestas a la sexta pregunta:}

$\rightarrow 16 \%$ respondieron el número $05.52 \%$ respondieron el número 04 . 24\% respondieron el número $03.4 \%$ respondieron el número 01 . 4\% respondieron el número 0 .

\section{Respuestas a la séptima pregunta:}

$\rightarrow$ A la gran mayoría le gusta el logo. Muy pocas personas señalan lo contrario.

\section{Respuestas a la octava pregunta:}

$\rightarrow$ A la gran mayoría le parece atractivo, representativo, amigable, llamativo y simple. Muy pocas personas no dan una opinión precisa, simplemente optan por el "no me gusta". 


\subsection{Rediseño final del logotipo}

Las validaciones sugirieron una revisión final del logotipo, llevando a realizar unos últimos cambios y agregados.

Se complementó el trabajo de colores asegurando obtener el color perfecto bajo el sistema de color con cuatricromía, gracias a las referencias que los libros de color Pantone ofrecían. Se terminó por definir los colores básicos del logotipo.

El color celeste para el círculo, basado en color mixto puro, que seguía haciendo alusión a lo celestial, creando una perspectiva de simpatía, confianza y armonía, como ya mencionamos, este matiz está estrechamente relacionado con lo divino y simboliza valores supremos. Según el libro de nombre Psicología del color, se señala: "Los colores más apreciados son el azul con un $45 \%$ y el rojo con un $12 \%$ respectivamente" (Heller, 2012).

La silueta del perro cambió su color marrón por un magenta para lograr un apropiado contraste con celeste y buena presencia dentro de la composición. El color magenta da una perspectiva de calidez, empatía y familiaridad. La combinación de estos dos matices, psicológicamente y físicamente contrarios (complementarios) logran un contraste simbólico de activo-pasivo, caliente-frío, alto-bajo, corporal-espiritual, masculino-femenino. Según Gael Towy, director creativo de Gael Towey y Co: “El color crea emoción, desencadena recuerdos y nos aporta sensaciones" (Wheeler, 2018).

Finalmente, el tono blanco en las alas del perrito pretende aludir a la pureza de un ángel volando al cielo. Transmite una imagen de bondad, pureza e inocencia y simboliza paz, humildad y amor. La tipografía mantuvo la fuente Sourvenir para el logotipo principal y Gill Sans para la bajada como la descripción del rubro de la empresa, por ejemplo. Se decidió así mantener todo el texto del logotipo en la misma línea base y con el mismo matiz para mantener la legibilidad. Es una fuente confiable, seria y brinda una percepción de carisma y cercanía, con el fin de que el cliente establezca una relación de confianza con la marca, muy importante porque el rubro de la empresa juega con un tema delicado para los clientes (figura 2.6). 
Figura 2.6

Diseño final del logotipo

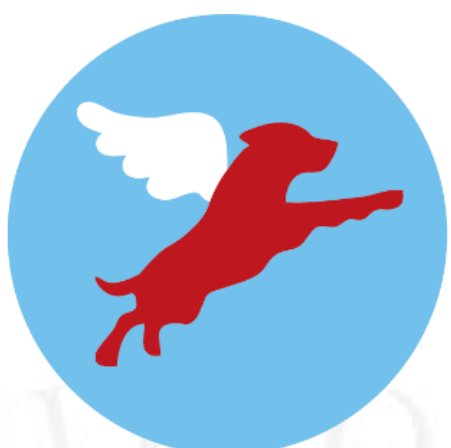

\section{CREMASCOTAS}

Cremación para animales domésticos 


\section{CAPÍTULO III: LECCIONES APRENDIDAS}

- Muchas empresas encuentran un inesperado y rápido éxito en sus emprendimientos y de la mano con esta vorágine se topan una necesidad imperiosa en el mercado moderno: el desarrollo de una marca sólida. Los logotipos se suelen trabajar de manera incipiente al principio, sin gran inversión de tiempo o dinero, generalmente con planteamientos de profesionales improvisados o del mismo cliente. Pero este último es quien se da cuenta de la posterior importancia de contar con una marca mejor trabajada.

- Muchas veces los trabajos de comunicación para una empresa empiezan con encargos aparentemente sencillos, y el desarrollo de estos revela, poco a poco otras necesidades. En nuestro caso la relación con Cremascotas inició con encargo de piezas promocionales para luego decantar en el planteamiento de una nueva imagen gráfica y terminar con la elaboración de un manual de identidad.

- Por más que el comunicador sugiere y da alternativas apoyado en investigaciones, bibliografía o experiencia previa, es el cliente quien al final tiene la última palabra y realiza modificaciones a aquello que se trabajó con tanta seriedad. Es necesario que el nuevo empresario se eduque en el reconocimiento de las cualidades que un buen trabajo de identidad visual ofrece. Muchas de las sugerencias para piezas gráficas no se tomaron en cuenta y son cosas que, lamentablemente, escapan de la mano del comunicador.

- Los manuales de identidad visual no solo traen consigo características sencillas de construcción, color y tipografía del logotipo, exigen además cuestiones técnicas que las universidades y la academia dejan de lado, seguramente por falta de tiempo. Hay muchos factores técnicos que se deben tomar en cuenta y que son parte de la educación que la experiencia y el tiempo en el mercado ofrecen. 


\section{CAPÍTULO IV: LOGROS Y RESULTADOS}

El cliente está bastante satisfecho con las propuestas iniciales del logotipo, sobre todo con aquellas planteadas durante el año 2018. Es por eso que muchas piezas gráficas realizadas para y por la empresa durante el 2019 usan el logotipo con las características antiguas.

La empresa renovó de inmediato su imagen institucional y decidió posicionar la nueva identidad en su mercado chiclayano y piurano para empezar a hacerla más conocida y, según sus declaraciones, ha venido teniendo una buena acogida por parte de su público objetivo.

Se elaboraron piezas gráficas como banners para eventos, polos para los colaboradores, volantes y las tarjetas de presentación.

La nueva imagen gráfica también ha sido aplicada para una mejor difusión en las redes sociales principalmente Facebook e Instagram (se adjunta las fotos en Anexos).

Para beneficio de la empresa, se ha mejorado la imagen corporativa, generando más ventas y una gran acogida de los clientes tanto chiclayanos como piuranos. 


\section{REFERENCIAS}

Hernandez, A. (2018). Perrolandia - Servicio para mascotas. 16 de Mayo, de Behance Sitio web: https://www.behance.net/gallery/65690503/Perrolandia-Serviciopara-mascotas

Wheeler, A. (2018). Diseño de Marcas. España: Anaya Multimedia.

Heller, E. (2012). Psicología del Color. Barcelona: Gustavo Gil, SL

Montesinos, L. M. (2003). Manual de Tipografía. Valencia: Campgráfic.

Washington Post. (2015). Perú, país perruno. 23 de Marzo, de Ipsos Sitio web: https://www.ipsos.com/es-pe/peru-pais-perruno 
ANEXOS 


\section{Anexo 1: Encuestas hacia el público objetivo}

1)¿Tienes Mascotas?( si tu respuesta es "NO" se finaliza la encuesta)

35 respuestas

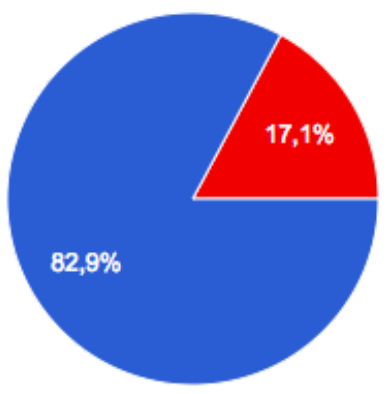

$\mathrm{SI}$

2)¿Qué tipo de mascotas tienes?

30 respuestas

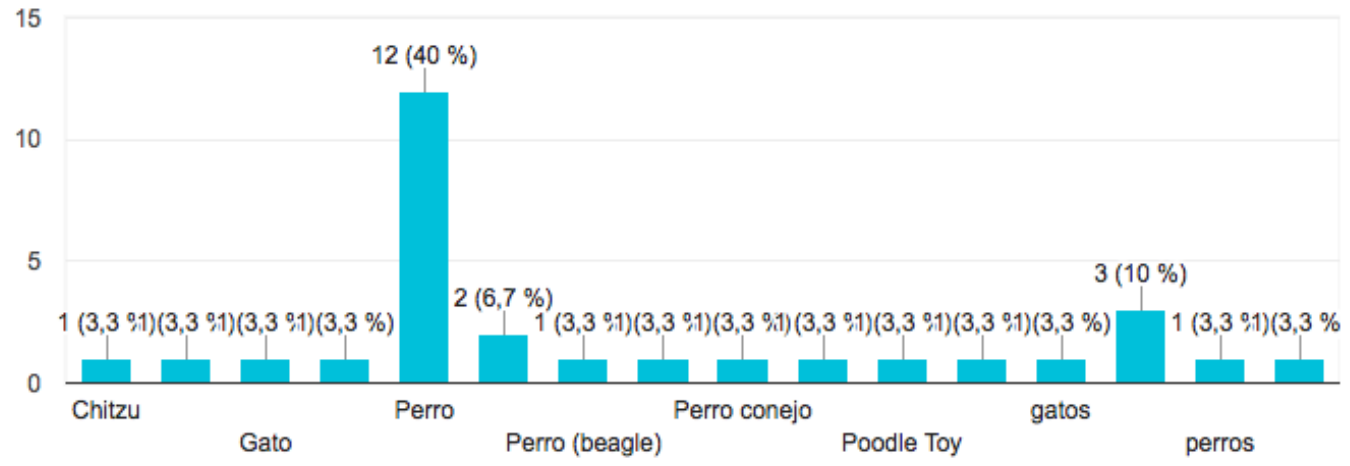


3) si tu mascota falleciera ¿Qué piensas hacer?

29 respuestas

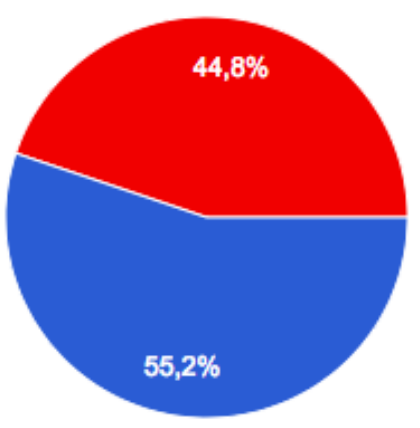

Enterrarla

Cremarla

\section{4) ¿Donde cremarias o enterrarias a tu mascota?}

\section{8 respuestas}

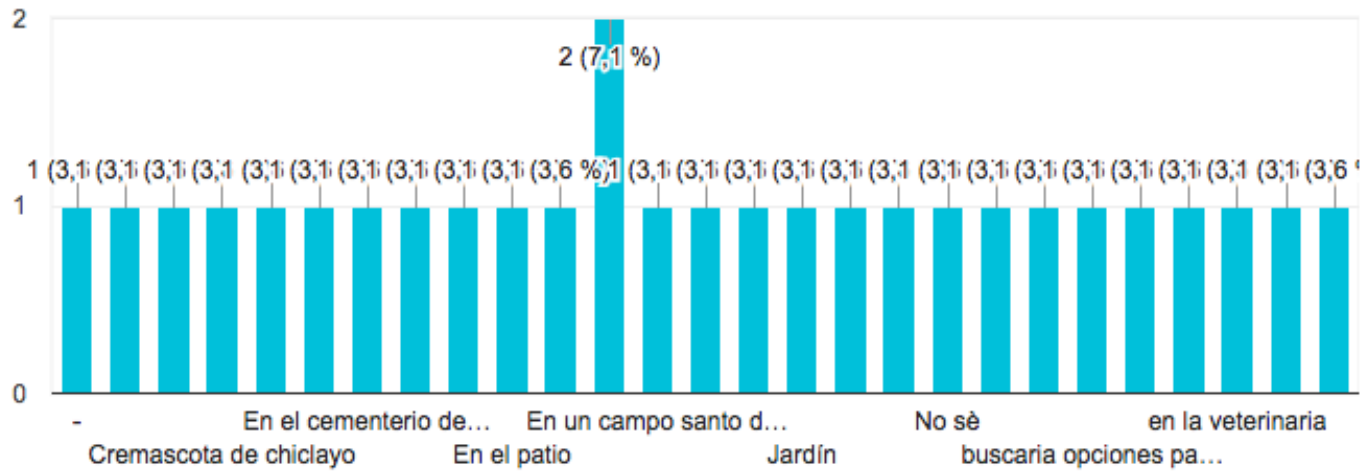




\section{5)¿Quién decide cremarlo o enterrarlo?}

29 respuestas

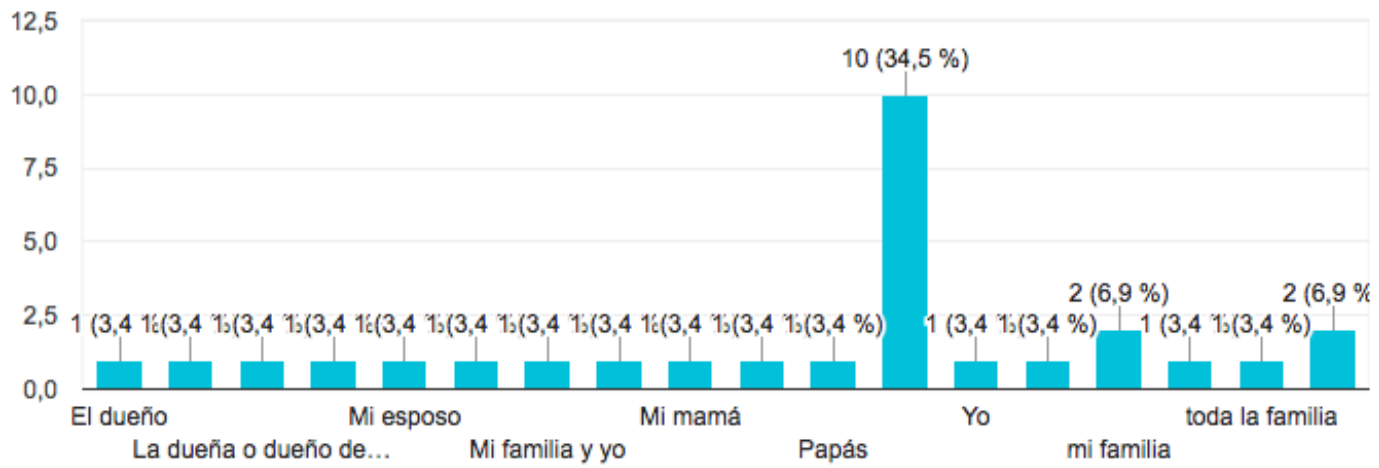

\section{6) ¿Estas de acuerdo con esta nueva modalidad de "cremar mascotas"? ¿Por} qué?

29 respuestas

\section{$\mathrm{Si}(2)$}

Mas o menos ya que vi una propuesta interesante en la que se creman las mascotas y las cenizas se usar para sembrar un arbol

No

si, porque la mascota es para de la familia y no todos tienen jardin para poder enterrar a la mascota y el cremar es una alternativa para las personas que viven en apartamentos

no, prefiero que las entierren.

Sí estoy de acuerdo, pero no creo que lo haga porque cremar es más caro que enterrar

Creo que si. Pero no lo haría

Si,porque hay gente q quisiera a sus mascotas mas cerca

$\mathrm{Si}$, pero la que luego se convierte en planta porque me parece una linda manera de recordarlo

No, porque soy católica

Sí porque me gustaría tener su recuerdo en una caja

$\mathrm{si}$, porque las mascotas estarian en cualquier parte de nuestro hogar su recuerdo y si se presentara un viaje podriamos llevar sus cenizas junto a nosotros

Si. Para mantenerlo siempre contigo

$\mathrm{Si}$, para perpetuar el recuerdo de mi mascota

$\mathrm{Si}$, porque es una nueva de enterrar una mascota

$\mathrm{Si}$, es una forma de conservarlo y recordarlo y así lo hagan mis descendientes

Podría ser, y asi guardar sus cenizas.

$\mathrm{Si}$, porque es bastante práctico

Depende, en particular yo no cremaria a mi perro; pero si es una opcion viable para varias personas.

Si porq asi cuidamos el medio ambiente y tambien conservas sus cenizas

Si porq asi cuidamos el medio ambiente y conservo las cenizas de mi mascota

No, no me gusta la idea de cremar mascota o a las personas, prefiero una sepultura.

Creo que es menos tedioso que enterrar a una mascota grande o de regular tamaño en el jardín, aparte no todos 
si , porque las mascotas estarian en cualquier parte de nuestro hogar su recuerdo y si se presentara un viaje podriamos llevar sus cenizas junto a nosotros

Si. Para mantenerlo siempre contigo.

$\mathrm{Si}$, para perpetuar el recuerdo de mi mascota

$\mathrm{Si}$, porque es una nueva de enterrar una mascota

Si, es una forma de conservarlo y recordarlo y así lo hagan mis descendientes

Podría ser, y asi guardar sus cenizas.

$\mathrm{Si}$, porque es bastante práctico

Depende, en particular yo no cremaria a mi perro; pero si es una opcion viable para varias personas.

Si porq asi cuidamos el medio ambiente y tambien conservas sus cenizas

Si porq asi cuidamos el medio ambiente y conservo las cenizas de mi mascota

No, no me gusta la idea de cremar mascota o a las personas, prefiero una sepultura.

Creo que es menos tedioso que enterrar a una mascota grande o de regular tamaño en el jardín, aparte no todos

\section{Anexo 2: Entrevistas a especialistas para validar el logotipo}

(2018)

\section{- Miguel Bernal Quijano opinó:}

"Los nuevos logotipos están más sencillos, pero lo que me preocupa es la tipografía: es muy legible y muy dura con el tema que estás tratando, ya que hay cierta solemnidad con la cuestión de entierro, cremaciones por cierto animalito, la solemnidad hay con tipografías romanas como las distintas variedades: garralda, caslo, souvenir que se 
inclina a lo tradicional, se parece más a una veterinaria que a una empresa que crema animales. Por otro lado, el logo que es una pata con alas se pierde; mejor sería el animal con alas y que ambos sean sólidos ya que si se quedan como línea se pierde en los logotipos, celeste el color de alas, sin detalles ya que recuerda que un logotipo debe ser funcional ya que en otros distintos soportes dichos detalles se van a perder y se verá como una mancha, que solo sea lineal. La raza del animal debe ser más tierno y adulto ya que es un entierro y es de animales. Más me fijaría en el isotipo y me inclinaría a lo cálidos rojos, naranja, amarillos y magentas ya que son colores familiares, sensoriales y cercanos no colores fríos ya que se alejan. Los elementos del logo como el ala debe ser un color sólido no difuminado de preferencia blanco y el círculo que encierra al perro debe ser color celeste u otro que combine. La medida del círculo debe de ver un espacio limitado entre la silueta del perro con el círculo. Al igual que las letras de cremascotas debe de ser el mismo color que el perro para evitar que haya tantos colores en la hora de imprimir. Después, en líneas generales está bien el logo". "Los elementos del logo como el ala debe ser un color sólido no difuminado, de preferencia blanco y el círculo que encierra al perro debe ser color celeste u otro que combine. La medida del círculo debe de ser un espacio limitado entre la silueta del perro con el círculo. Al igual que las letras de cremascotas debe de ser el mismo color que el perro para evitar que haya tantos colores en la hora de imprimir".

\section{- Alberto Matsuura Sonoda opinó:}

"Está mejor, más icónico el isotipo pero se puede mejorar con el fondo del círculo del logo principal para que haya más contraste con el soporte del volante y lo otro es el banner: le falta mejorar con el tema del color, no es tan llamativo ya que no se aprecia mucho y al mismo tiempo no va a llamar la atención de la gente”. 


\section{Anexo 3: Entrevistas a especialistas para validar el manual de marca y el logotipo renovado (2019)}

\section{a) Claudia Torres opinó:}

"Anatómicamente la parte del brazo, del omóplato del perro, cuello no está estándar, debe estar proporcionada. CRE debe de resaltar más que MASCOTAS, visualmente. Mientras más armónica es mejor en el logo. CRE se puede cambiar el color, tamaño, la tipografía más gruesa, cursiva o ponerle outline dependiendo del fondo, ya que ahí se ve más contraste MASCOTAS que con el CRE. Ver cómo quieres que se vea el logo, si a la derecha o la izquierda que es lo que quieres que se lea primero o segundo, es decir, es arreglar proporciones.

Visualmente está alineado a esto y se siente que se va para arriba. De repente te conviene bajar el círculo para que se vea un poco centrado, cuando el logo está a un costado. En un solo color se ve mejor. Qué colores vas a usar en tu paleta siempre, si es color marrón o celeste usarlo. Mejora el color del polo, es rosado o lila.

Tus materiales deberían de tener el logo.

Deberías de hacer un volante troquelado de la nube, trata que toda tu marca respire el mismo sentido, debería de participar algo de celeste o marrón, ponerle una franjita o algo que identifique que esa imagen es tuya, tu marca, que no es una foto cualquiera que hayas sacado de pinterest por ejemplo.

Trata de personalizar, si no tratas de buscar un filtro que sea para tus imágenes, tratar de ponerle un elemento, o un color corporativo y siempre acompañado del logo.

Tratar de alinear todo a la misma sensación gráfica, es básicamente proporción y ver la legibilidad del CRE y alinear tus elementos gráficos para que todo sea uno solo”.

\section{b) Alberto Matsuura Sonoda opinó:}

“Las imágenes deberían ser cercanas al tema más peruano y no gringo. Trata de tomar las fotos: le va dar más cercanía a la propuesta. Algunas páginas del manual de marca en la parte inferior no aparecen del logo. Hay que resaltar el tema de los productos, en el sentido de la foto, es demasiado grande a comparación de los productos, debería de 
ser una lista de los productos y de repente una imagen que grafique cada uno de esos productos, en todo el caso iconos o fotos, depende de ti, debe ser algo gráficamente que el producto me está ofreciendo.

Respecto al logo, no ayuda con el tema de las fotos. Debería ser de forma más gráfica, creo que es la forma como juntas dos elementos y no más páginas. En un solo ppt poner esto más esto te resulta esto, acompañado de un texto que te explique el concepto rápidamente que refuerce.

Lo que sí me llama la atención del logo debería de funcionar el perrito de un solo color con las alas, porque cuando se separan ambas con distintos colores ahí hay un problema, ya que el perro color negro y el ala blanca. Lo siento diferente que el ala más el perrito tiene dos cosas, no lo siento integridad. Debería de ser un solo color. Hay otra cosa que no lo has definido: el logo principal, el círculo celeste y el perrito en blanco y las variantes en negativo, blanco y negro, blanco y negro en negativo faltaría. El área de seguridad no se toma el área del isotipo ya que si lo aplicas en otro lado, el área de seguridad va a ser muy grande ningún elemento va alcanzar, es mejor que agarres la letra C. Los usos correctos debes darle un orden. Trata de que sea un celeste más constante, es mejor el color celeste vivo y el estilo que le quieras dar".

\section{c) Diseñador gráfico de la Upc, Javier Custodio opinó:}

"Podría mejorar: el uso incorrecto del logo, utilizar colores pantone, modificar los usos de la tipografía y que haya los usos incorrectos y correctos del logo”. 


\section{Anexo 4: La encuesta hacia el público objetivo para saber qué opinan acerca del logotipo (2019)}

1) ¿A qué tipo de empresa cree que pertenece este Logotipo?

25 respuestas

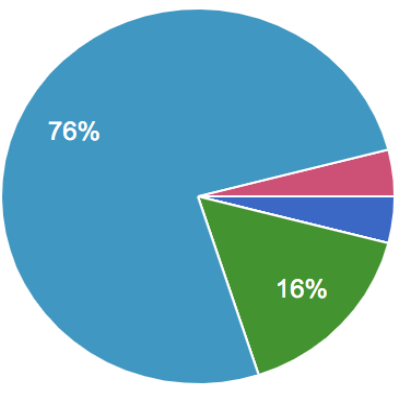

$$
\begin{aligned}
& \text { Veterinaria } \\
& \text { Zoologico } \\
& \text { Paseador de Mascotas } \\
& \text { Cementerio } \\
& \text { Comida para Perros } \\
& \text { Cremación de Mascotas } \\
& \text { Clinica de Mascotas } \\
& \text { Ropa para Perros } \\
& 1 / 2
\end{aligned}
$$

2) Es una empresa que se encarga de la cremación de mascotas. ¿Del 0 al 5 , que tanto se asocia este logotipo a la empresa?

\section{5 respuestas}

\section{5}

10

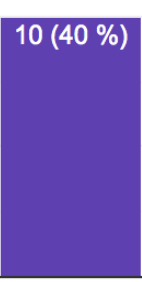

5

0
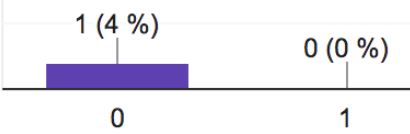

$1(4 \%)$

$1(4 \%)$

2

3 
3)¿Del 0 al 5, este logotipo representa una empresa confiable y seria? 25 respuestas

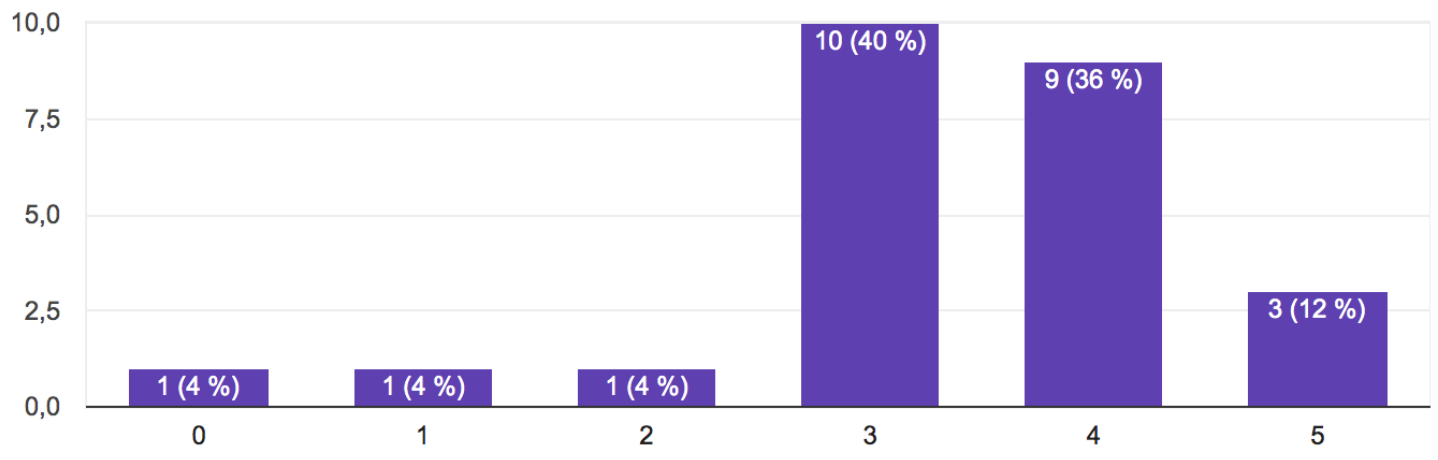

4) ¿Del 0 al 5, este logotipo representa una empresa económica y barata?

25 respuestas

15

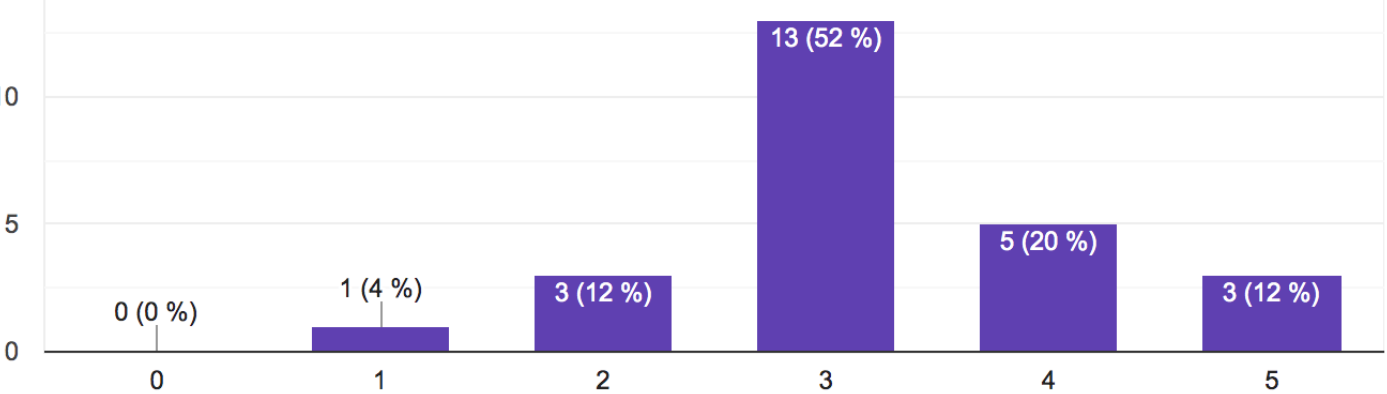


5)¿Del 0 al 5, este logotipo representa una empresa amigable y amorosa?

25 respuestas

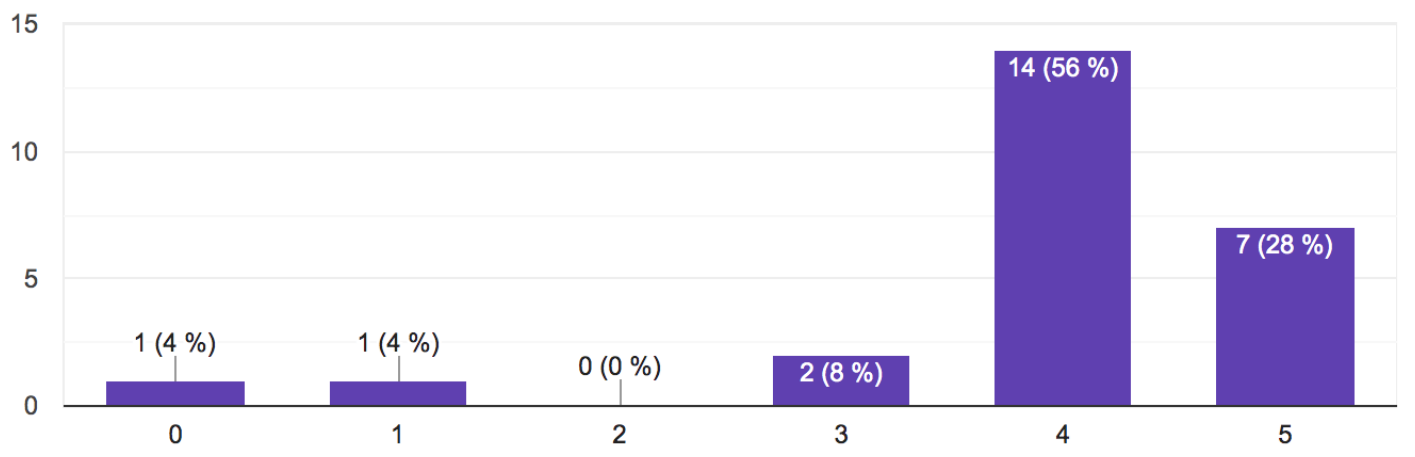

6) ¿Cree usted que al ver este logotipo, traten bien al cuerpo de tu mascota?

25 respuestas

15

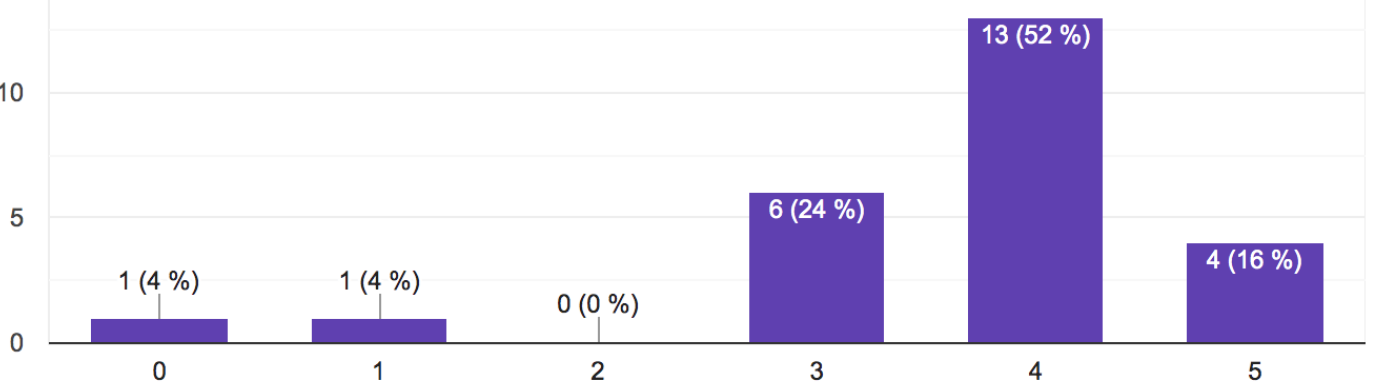




\title{
7) ¿Te parece atractivo, te gusta? ¿Qué tanto te gusta el Logotipo? Díganos: ¿Por qué?
}

25 respuestas

\author{
$\mathrm{Si}$, esta interesante \\ Sí mi gusta porque es colorido y creativo \\ Me genera un poco de pesar \\ Si porque tiene relación con el objetivo
}

La imagen

Creo que le falta un poco de sentimiento, normalmente las mascotas son relacionadas con cosas amorosas, pero el logotipo está un poco frío

Si me parece atractivo, por los colores

Mas o menos. Esta muy sintetizado la imagen del perro, como si fuera ajeno (se sabe que como mascota significó mucho) y el color marrón no favorece, tal vez un color claro.

No

Me parece atractivo que el perrito tenga alitas de ángel y esté volando en el cielo. Me parece súper tierno y me transmite el mensaje que aunque el perrito ya no esté en la tierra, él está feliz en el cielo.

Sí. Sona singelo y indica cariño. Pasa confianza.

Le falta algo más de seriedad, formalismo .. nose

Es amigable y reconfortante el logo

Da confianza

Representa mucho

Refleja bastante el core de la empresa

Si es atractivo y me gusta, me gusta bastante, por que representa lo que uno busca de sus seres queridos q estén cerca de alguna manera después q se fueron al cielo

Si me parece atractivo por que tiene formas redondeadas y colores claros.

Me gusta, pero al principio pensé que era un cementerio de perros. Quizá deberían hacerlo más minimalista, pero que se siga notando que es un perro.

si, mucho porque tiene mucho que ver con la cremación de mascotas

Me gusta pero creo que se le podria cambiar los colores a unos mucho más neutrales por el servicio que brindan

Si me parece atractivo, tal vez la paleta de otros colores

Si me gusta, es innovador

Me gusta por que las Alas representa que los animales también merecen descansar en paz.

$\mathrm{Si}$ 


\section{8) De la pregunta anterior: Díganos, en 3 palabras. ¿Por qué te gusta el logotipo?}

25 respuestas

simple y llamativo

Color, letra y dibujo

Es minimalista

Buen servicio

El perro con alas

Creo que es muy celeste, deberían utilizar un color más cálido que te de una presencia de amor o de snetimientos Colores, forma del logo con alas y el texto Cremascotas.

Me gustan las alas que lleva el perrito pero no me cuadra aún la síntesis o "pregnante" del perrito.

No me gusta

Tranquilidad, ternura, esperanza

Me gusto de las alas en el perrito.

Cercanía , amor a los animales, cuidado de listo animales

Amigable, reconfortante y respetuosa del luto

Tierna

Sencillo, relaciona mucho el tema, da confianza.

Refleja la empresa

Porque es claro, amigable y representativo.

Amigable, simple, minimalista

Los colores son bonitos y generan tranquilidad,

es amigable, interesante y creativo

Porque esta bien sintetizado

Representa bien el rubro del negocio

Innovador, creativo, confiable

Original, Colorido y Representativo

Sencillo y bonito 


\section{Anexo 5: El logotipo del año 2018 se utilizó en las dos redes sociales: Instagram y Facebook}

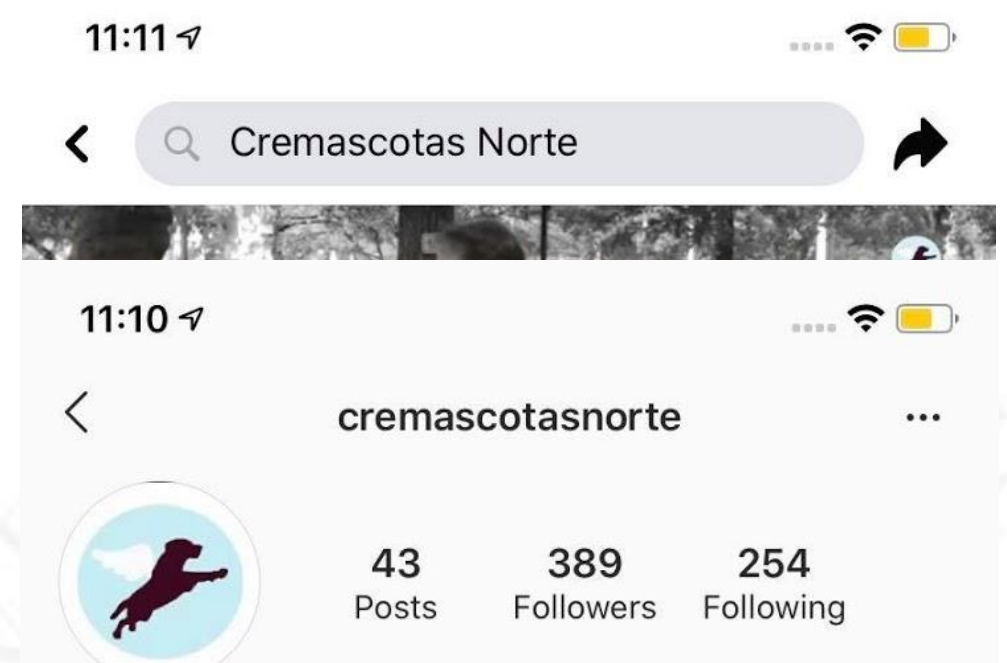

Cremascotas Norte

Veterinarian

Somos una empresa dedicada al servicio de cremación para mascotas domésticas en el Norte del Perú. (.0) Facebook y YouTube: Cremascotas Norte www.cremascotasnorte.com Followed by estefidavila and madicloths See Translation
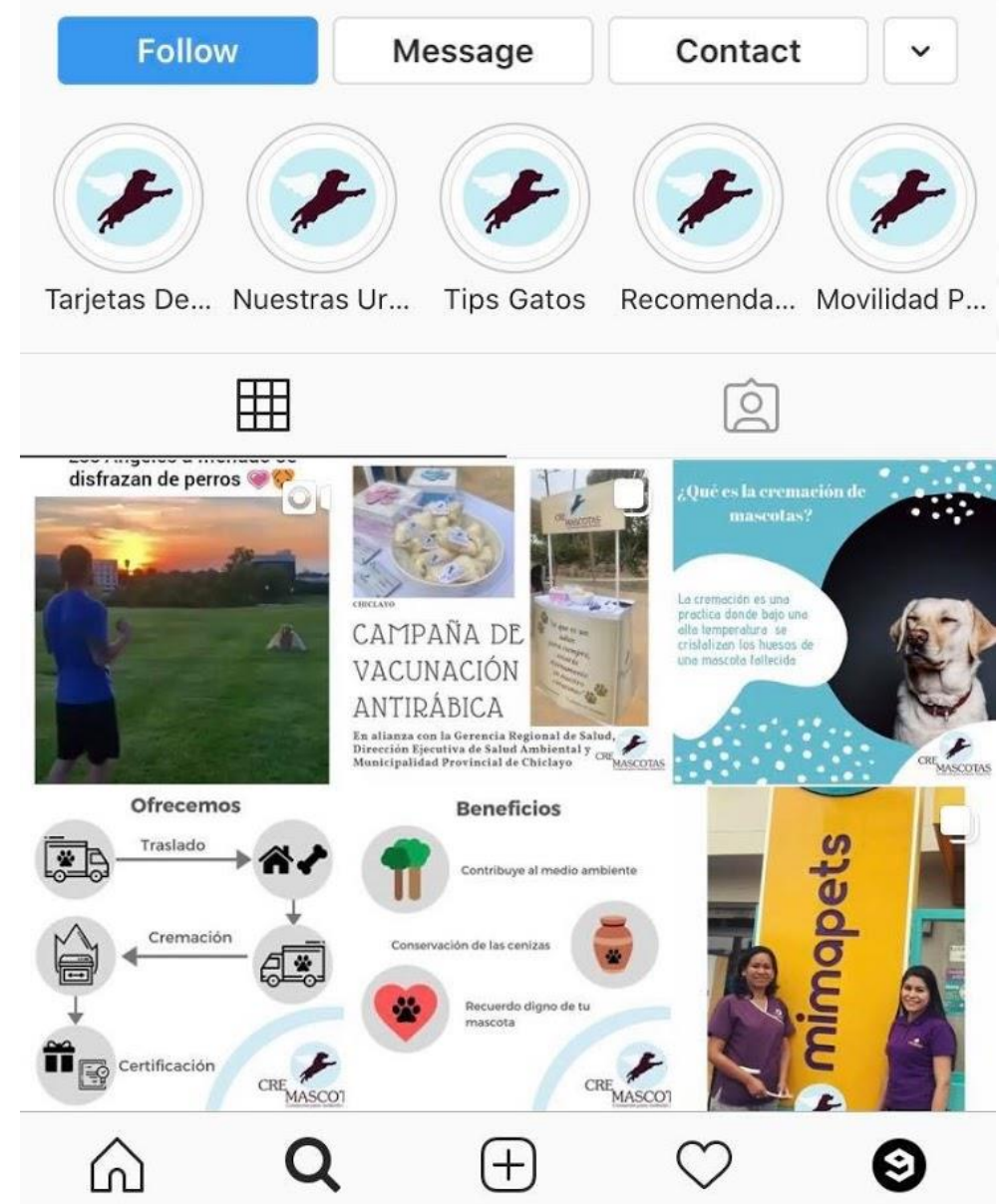